\title{
The prevalence of depression among patients with tuberculosis: a systematic review and meta-analysis
}

\author{
Bereket Duko ${ }^{1,2^{*}} \mathbb{D}$, Asres Bedaso ${ }^{1}$ and Getinet Ayano ${ }^{2,3}$
}

\begin{abstract}
Background: Evidence has shown that the prevalence of depression is much higher among patients with tuberculosis (TB) and this, in turn, may adversely impact compliance with anti-TB medications. Therefore, this systematic review and meta-analysis aimed to quantitatively summarize epidemiologic evidence on the prevalence of depression among patients with TB and formulate a recommendation for future clinical practice as well as research.

Methods: We followed the preferred reporting items for systematic reviews and meta-analyses (PRISMA) guidelines to conduct this review. We searched PubMed, EMBASE, SCOPUS and Psych INFO to identify relevant studies that investigated the prevalence of depression among TB patients. We also supplemented our electronic search with manual searching to include all pertinent studies in the analysis. We used a Comprehensive Meta-Analysis software version 3.0 (CMA 3.0) to conduct a meta-analysis. We conducted a subgroup and sensitivity analysis and Cochran's Q- and the $P^{2}$-statistics were used to assess heterogeneity. The evidence for the presence of publication bias was checked by using Egger's test and visual inspection of the symmetry in funnel plots.

Results: We identified a total of 25 studies that included 4903 participants across seven countries. In our analysis, the pooled estimated prevalence of depression among TB patients was found to be $45.19 \%$ (95\% Cl 38.04-52.55). The prevalence was higher in MDR-TB 52.34\% (95\% Cl 38.09-66.22) than non-MDR-TB 43.47\% (95\% Cl 35.88-51.37) patients. We also found that the pooled prevalence of depression was higher among females $51.54 \%(95 \% \mathrm{Cl} 40.34-$ 62.60) when compared to males $45.25 \%$ ( $95 \% \mathrm{Cl} 35.19-55.71)$. The pooled prevalence of depression was $45.45 \%$ as measured by HRDS, and it was 55.62\%, 45.52\%, and 38.36\% as measured by BDI, HADS and PHQ-9, respectively.

Conclusion: Our finding suggested that the pooled estimated prevalence of depression among tuberculosis patients was relatively high. Screening and management of depression among TB patients were warranted to alleviate suffering. Moreover, the integration of tuberculosis program with regular psychiatry services may substantially reduce the burden.
\end{abstract}

Keywords: Prevalence, Depression, TB, Systematic review, Meta-analysis

*Correspondence: berkole.dad@gmail.com

${ }^{1}$ Faculty of Health Sciences, College of Medicine and Health Sciences, Hawassa University, Hawassa, Ethiopia

Full list of author information is available at the end of the article

\begin{abstract}
Background
Tuberculosis (TB) a chronic infectious disease, which is caused by Mycobacterium tuberculosis (MTB) bacteria, affects the lungs and other parts of the body [1]. The World Health Organization (WHO) report of 2019 showed that approximately 10 million people fell ill with TB, 1.5 million people died of TB and 484,000 people fell ill with drug-resistant TB in 2018 [2]. On the other hand,
\end{abstract}


58 million people lives saved between 2000 and 2018 by efforts to end tuberculosis globally [2]. However, the high burden of TB on morbidity and mortality constitutes a significant concern in low and middle-income countries $[2,3]$. Numerous risk factors have been associated with mortality that resulted from poor anti-TB medication adherence. Poor compliance with medications may lead to treatment default and result in severe medical complications, for example, multidrug-resistant TB (MDR-TB) [4].

Depression is among common mental health problems that occur in patients with tuberculosis, characterized by persistent depressed mood, lack of pleasure in everyday activities, reduced energy, vegetative symptoms, suicidal ideation and attempt and causing varying levels of social and occupational dysfunctions [5]. Depression is a major contributor to the overall global burden of disease and affected more than 264 million people of all ages in 2019 [6]. Findings from different studies showed that approximately 800,000 people die due to suicide every year and over $50 \%$ of all people who die by suicide suffer from major depression [7, 8]. Evidence from the epidemiological study also showed that the lifetime risk of suffering from depression among the general population is $7.2 \%$ and $4.4 \%$ in females and males, respectively [9].

Depression and tuberculosis are often coexisting in individuals. They share common risk factors, which suggest the high magnitude of their comorbidity as reported by different studies to range from 10 to $52 \%$ [10, 11]. For example, the increase of pro-inflammatory cytokines characteristic of depression leads to reduced activation of the cellular and humoral immune systems and this, in turn, contributes to the progression of tuberculosis [11]. Similarly, infection resulted from tuberculosis can cause chronic inflammation, releasing pro-inflammatory cytokines that stimulate enzymes functioning at the central nervous system and also some of the anti-TB medications may play a role in mental health problems such as depression [12]. When depression is comorbid with tuberculosis, it will lead to poor quality of life, lack of adherence to anti-Tb medications, progressions to MDR$\mathrm{TB}$ and finally end up with mortality resulting from the disease [13, 14].

Epidemiological findings from different studies showed different rates of prevalence of depression among patients with tuberculosis [15-19]. For example, a cross-sectional study that assessed the prevalence of depression among tuberculosis patients in Pakistan reported 47.2\% [15]. In contrast, another cross-sectional study from Greece that assessed the prevalence of depression in patients with bronchial asthma, chronic obstructive pulmonary disease, and tuberculosis in a general hospital of chest diseases reported 9.93\% [16]. The disparities in the rates of prevalence may be attributed to variations in the assessment tools of depression among TB patients.

A systematic review and meta-analysis was conducted in 2018 to quantify mental health problems such as depression, anxiety, and psychosis as well as the healthrelated quality of life in patients with multidrug-resistant tuberculosis (MDR-TB) [20]. This review included a total of 32 studies that assessed mental health problems including substance use disorders among MDR-TB patients across 20 countries and estimated the prevalence of mental health problems at baseline and after MDR-TB treatment initiation. This study reported that the pooled estimated prevalence of depression, anxiety, and psychosis among MDR-TB patients was $50 \%, 16 \%$, and $4 \%$, respectively, before initiation of the tuberculosis medications. However, our review focuses on the prevalence of depression among tuberculosis patients irrespective of the severity of tuberculosis (MDR-TB or non-MDR-TB). Therefore, this study aimed to quantitatively summarize the prevalence of depression among TB patients and formulate a recommendation for future clinical practice as well as research.

\section{Methods}

\section{Search strategy}

We performed an extensive search of literature as suggested in the guideline of reporting systematic review and meta-analysis (PRISMA) [21]. We have reviewed both published and gray literature on the prevalence of depression among patients with tuberculosis using the following major databases: PubMed, SCOPUS, EMBASE, and Psych INFO. All published and unpublished articles up to December 2019 were included in the systematic review and meta-analysis. We conducted our search in PubMed using the following terms: "depression OR depressive disorder OR major depression OR depressive symptoms OR mental health problems OR distress OR psychological distress AND tuberculosis OR TB OR MDR-TB OR respiratory disease AND prevalence OR magnitude OR epidemiology OR incidence". We used specific-subjects headings for EMBASE and SCOPUS database searching. Besides, we have manually searched the reference lists of eligible articles.

\section{Eligibility criteria}

Evaluation of the relevant studies using their title and abstract was done before the retrieval of full-text articles for further screening, the two reviewers (BD and GA). A predefined inclusion and exclusion criteria were employed to screen the retrieved full articles and any disagreement during the process was solved via discussion with a third reviewer (AB). Cross-sectional and other observational studies that assessed the prevalence of 
depression among patients with tuberculosis (MDR-TB and non-MDR-TB patients) and published in the English language were included in the review. Duplicate studies, commentaries, reviews, letters, editorials, and short communications were excluded from the review.

\section{Methods for data extraction and quality assessment}

A predesigned standardized data extraction form was utilized to extract data from the studies included in the systematic review and meta-analysis. We have extracted the following information from each study: the name of the first author, publication year, study setting, study design, sample size, the prevalence of depression and data measurement tools used for assessing depression. Two reviewers extracted the data from the included studies independently and any disagreements raised during data extraction were resolved through discussion with a third reviewer. A modified version of the NewcastleOttawa Scale (NOS) [22] was used to evaluate the quality of the included studies. An ascertainment of depressive symptoms, statistical quality, sample representativeness, sample size and comparability between participants were the domains NOS scale to assess the quality of individual studies.

\section{Data synthesis and analysis}

We used a comprehensive meta-analysis software version 3.0 (CMA 3.0) to conduct this meta-analysis. The random effect meta-analysis model was used to estimate the overall pooled estimated prevalence of depression among patients with tuberculosis. The Q- and $I^{2}$-statistics were used to check the heterogeneity among the studies included in the review [23]. The magnitude of statistical heterogeneity between studies was assessed using $I^{2}$-statistic and values of 25, 50 and 75\% were considered to represent low, medium and high, respectively $[24,25]$. We have used subgroup and sensitivity analysis to explore the potential source of heterogeneity. The data assessment instrument that was used to assess depression, types of tuberculosis (MDR-TB and non-MDR$\mathrm{TB})$, the gender of the study participants and the quality of studies were used to determine the possible source of heterogeneity between the studies. The funnel plot and Egger's regression tests were checked to assess publication bias.

\section{Results}

\section{Identification of studies}

Our electronic search engine and strategies resulted in a total of 739 articles. Additionally, we identified 9 articles by our manual search making the total articles of 748 . Of these, 595 were excluded during the evaluation of duplicate and titles as they did not meet the inclusion criteria.
Our appraisal of abstract resulted in the exclusion of a further 117 articles. Therefore, a full-text of 36 studies were retrieved for further evaluation and 11 of these were excluded (Fig. 1).

\section{Characteristics of included studies}

In this review, a total of 25 studies were included in the final meta-analysis conducted in seven countries representing 4903 participants. The characteristics of the study populations included in this study are depicted in Table 1. Out of 25 studies included in the review, seven were from Pakistan [15, 26-31], seven from India [3238], three from Nigeria [18, 39, 40], four from Ethiopia $[11,19,41,42]$, one from Brazil [43], one from China [44], one from Cameron [45], and one from Turkey [47]. The studies included in this review were published between 2006 and 2019, with the sample size ranging between 45 participants in India and 1252 participants in China. Depression among TB patients was predominantly measured using the PHQ-9 scale. The PHQ-9 was used in 12 studies, HADS in 7 studies, BDI in 3 studies, and the HDRS in 3 studies.

\section{Quality of included studies}

The Newcastle-Ottawa scale (NOS) scale with slight modifications was used to evaluate the quality of studies included in the review. Of the included studies, nine studies were high quality (NOS score 8 and above), nine moderate quality (NOS score between 6 and 7 inclusive) and seven were low-quality studies (NOS score less than or equal to 5 ) (Table 1 ).

\section{Meta-analysis \\ The prevalence of depression among patients with tuberculosis}

Twenty-five studies that reported the prevalence of depression among patients with tuberculosis were included in the final analysis (Table 1). Based on the results of the random-effects meta-analysis model, the pooled estimated prevalence of depression among patients with tuberculosis was $45.19 \%$ (95\% CI $38.04-$ 52.55). We found significant heterogeneity for this analysis $\left(I^{2}=96.28 \% ; p<0.001\right)$ (see Fig. 2).

\section{Subgroup analysis \\ The prevalence of depression in patients with MDR-TB and non-MDR-TB}

In this review, five of the studies reported the prevalence of depression in MDR-TB whereas 20 of them reported the prevalence of depression in non-MDR-TB cases. In the analysis of those studies which reported prevalence of depression among MDR-TB and non-MDR-TB cases, we found that the prevalence of depression was 


\section{Identifications}

Screening

$\begin{aligned} & \text { Records identified through } \\ & \text { data base searches }(n=739)\end{aligned}$
EMBASE $=161$
PubMed $=201$
SCOPUS $=304$
Psych Info $=73$

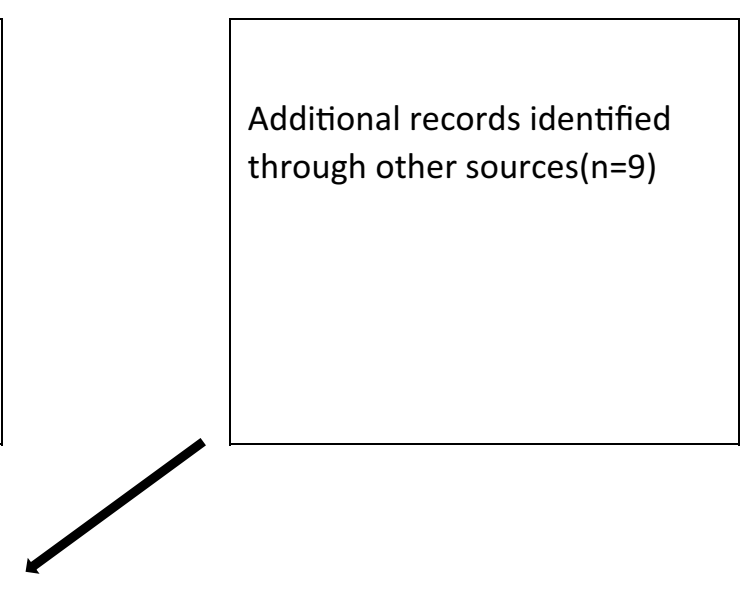

Records screened $(\mathrm{n}=748$

Records excluded (712)

Duplicate $=6$

Title review $=589$

Abstract review $=117$

Eligibility

Full text articles assessed

for eligibility $(n=36)$

Full text articles

excluded( $n=11)$

The study population was not $\mathrm{TB}(\mathrm{N}=4)$

Not measure the

prevalence $(n=5)$

duplicate $(\mathrm{N}=2)$

reviews $(\mathrm{N}=1)$

editorial $(\mathrm{N}=1)$

Included

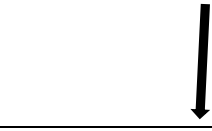

Full text included in qualitative and quantitative analysis $(n=25)$

Fig. 1 PRISMA flowchart of review search 
Table 1 Characteristics of studies included in the systematic review and meta-analysis

\begin{tabular}{|c|c|c|c|c|c|c|c|c|c|}
\hline Study name & Country & Sample size & Type of TB & $\begin{array}{l}\text { Year data } \\
\text { collected }\end{array}$ & $\begin{array}{l}\text { Depression } \\
\text { assessment } \\
\text { instrument }\end{array}$ & $\begin{array}{l}\text { Prevalence } \\
\text { in male (\%) }\end{array}$ & $\begin{array}{l}\text { Prevalence } \\
\text { in female } \\
(\%)\end{array}$ & $\begin{array}{l}\text { Overall } \\
\text { prevalence }\end{array}$ & $\begin{array}{l}\text { NOS quality } \\
\text { score }\end{array}$ \\
\hline Aamir et al. [26] & Pakistan & 65 & MDR-TB & 2007-2008 & HADS & & & 36.9 & Low \\
\hline $\begin{array}{l}\text { Anwar et al. } \\
\text { [27] }\end{array}$ & Pakistan & 60 & TB & 2009 & BDI-II & 86.1 & 70.8 & 80 & Low \\
\hline $\begin{array}{l}\text { Javald et al. } \\
\text { [28] }\end{array}$ & Pakistan & 289 & MDR-TB & $2012-2013$ & HDRS & 81.3 & 92.9 & 69.55 & High \\
\hline $\begin{array}{l}\text { Ahmed et al. } \\
\text { [29] }\end{array}$ & Pakistan & 83 & $\mathrm{~TB}$ & 2015 & HDRS & & & 49.4 & Low \\
\hline $\begin{array}{l}\text { Hussain et al. } \\
\text { [15] }\end{array}$ & Pakistan & 108 & TB & 2007 & HADS & 50 & 45.3 & 46.3 & Moderate \\
\hline $\begin{array}{l}\text { Amreen et al. } \\
\text { [29] }\end{array}$ & Pakistan & 100 & $\mathrm{~TB}$ & 2014 & PHQ9 & & & 56 & Moderate \\
\hline $\begin{array}{l}\text { Mehreen et al. } \\
\text { [30] }\end{array}$ & Pakistan & 213 & MDR-TB & 2013 & HDRS & & & 65.5 & High \\
\hline $\begin{array}{l}\text { Yilmaz et al. } \\
\text { [46] }\end{array}$ & Turkey & 208 & $\mathrm{~TB}$ & 2014-2015 & HADS & 60.3 & 61.0 & 60.5 & Moderate \\
\hline Ravi et al. [32] & India & 120 & $\mathrm{~TB}$ & $2017-2018$ & PHQ9 & 50 & 47.4 & 49 & Moderate \\
\hline $\begin{array}{l}\text { Kumar et al. } \\
\text { [33] }\end{array}$ & India & 100 & $\mathrm{~TB}$ & 2015 & BDI-II & & & 35 & Low \\
\hline Basu et al. [34] & India & 110 & TB & 2012 & PHQ9 & 72 & 72.7 & 61.8 & Moderate \\
\hline $\begin{array}{l}\text { Dahiya et al. } \\
\text { [35] }\end{array}$ & India & 106 & TB & 2016 & BDI-II & 42.86 & 77.3 & 50 & Moderate \\
\hline Arjun et al. [36] & India & 200 & TB & 2009-2011 & HDRS & 39.8 & 39.1 & 39.5 & Moderate \\
\hline $\begin{array}{l}\text { Chandra et al. } \\
\text { [37] }\end{array}$ & India & 100 & MDR-TB & 2014-2015 & HADS & 56.3 & 52.8 & 55 & Moderate \\
\hline $\begin{array}{l}\text { Mrinalini et al. } \\
\text { [38] }\end{array}$ & India & 100 & $\mathrm{~TB} / \mathrm{HIV}$ & 2012-2014 & PHQ9 & & & 16 & Moderate \\
\hline $\begin{array}{l}\text { Dos et al., } 2016 \\
\text { [43] }\end{array}$ & Brazil & 86 & MDR-TB & 2013 & HADS & 28.3 & 46.2 & 31.4 & Low \\
\hline Wang et al. [44] & China & 1252 & TB & 2014-2015 & PHQ9 & 18.4 & 16.76 & 17.7 & High \\
\hline Baba et al. [39] & Nigeria & 65 & TB & 2008 & PHQ9 & 29.3 & 25 & 27.7 & Low \\
\hline $\begin{array}{l}\text { Larson et al. } \\
\text { [40] }\end{array}$ & Nigeria & 371 & $\mathrm{~TB} / \mathrm{HIV}$ & 2013-2015 & PHQ9 & 29.9 & 26.9 & 30 & High \\
\hline Ige et al. [18] & Nigeria & 88 & $\mathrm{~TB}$ & 2010 & HDRS & 20 & 57.1 & 45.5 & Low \\
\hline $\begin{array}{l}\text { Kehbila et al. } \\
\text { [45] }\end{array}$ & Cameroon & 265 & $\mathrm{~TB}$ & 2015 & PHQ9 & 22.6 & 38.2 & 61.1 & High \\
\hline Duko et al. [19] & Ethiopia & 417 & TB & 2014 & HADS & 43.8 & 43.2 & 43.4 & High \\
\hline $\begin{array}{l}\text { Ambaw et al. } \\
\text { [11] }\end{array}$ & Ethiopia & 657 & TB & 2015 & PHQ9 & 49.7 & 58.1 & 54 & High \\
\hline Dasa et al. [41] & Ethiopia & 403 & TB & 2017 & PHQ9 & & & 51.9 & High \\
\hline Molla et al. [42] & Ethiopia & 415 & TB & 2018 & PHQ9 & 39.6 & 51.9 & 31.1 & High \\
\hline
\end{tabular}

higher in MDR-TB 52.34\% than non-MDR-TB 43.47\%. A significant heterogeneity was found in both MDR-TB $\left(I^{2}=92.55 ; p<0.001\right)$ and non-MDR-TB $\left(I^{2}=99.26 \%\right.$; $p<0.001$ ) (see Table 2).

\section{Subgroup analysis of the prevalence of depression} among TB patients by the assessment instrument

We also conducted a subgroup analysis by the type of assessment instruments used to measure depression. The pooled prevalence of depression was $45.45 \%, 55.62 \%$,
$45.52 \%$ and $38.36 \%$ for studies that assessed depression using HRDS, BDI, HADS and PHQ-9, respectively. The heterogeneity was significant for all studies performed by BDI $\left(I^{2}=79.38 \%, p<0.0001\right)$, HADS $\left(I^{2}=80.40 \%\right.$, $p<0.0001)$, HRDS $\left(I^{2}=87.87 \%, p<0.0001\right)$ as well as PHQ-9 $\left(I^{2}=97.63 \%, p<0.001\right)($ see Table 2$)$. 


\section{The prevalence of depression among TB patients: a meta-analysis}

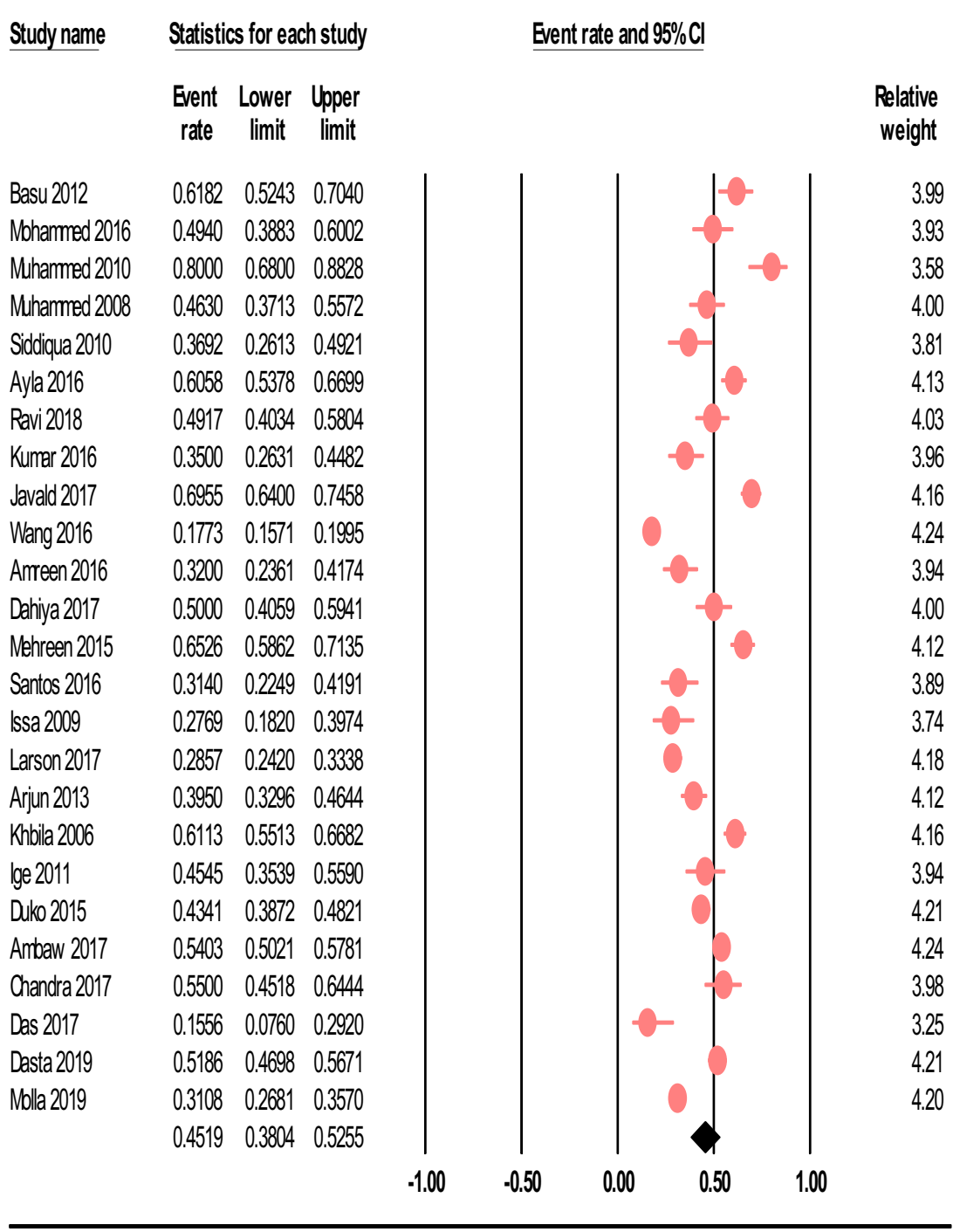

Keys:high $\left({ }^{2}=96.28 \%, P<0.0001\right) ;$ Based on random effect analysis

Fig. 2 Forest plot of the prevalence of depression among TB patients: a meta-analysis

\section{Subgroup analysis of the prevalence of depression} among TB patients by gender of participants

In this review, 17 of the studies reported the prevalence of depression in male and female participants. Analysis of those studies which reported prevalence of depression in males and females, we found that the prevalence of depression was higher in females 51.54\% (95\% CI 40.3462.60 ) than males $45.25 \%$ (95\% CI 35.19-55.71). A significant heterogeneity was found in both females $\left(I^{2}=92.55\right.$; $p<0.001)$ and males $\left(I^{2}=95.09 ; p<0.001\right)$ (see Table 2$)$.

\section{Sensitivity analysis}

To further investigate the potential source of heterogeneity in the analysis of the prevalence of depression among patients with TB, we conducted a sensitivity analysis by the type of depression, the assessment instrument used to measure depression, and the quality of the included studies. When limiting the analysis to studies reported depression among MDR-TB, the prevalence of depression was found to be, $52.34 \%$, as compared studies conducted on non-MDR-TB $43.47 \%$, even though the 
Table 2 Sensitivity analysis of all studies based on type of TB, instrument used, and study quality of the included studies

\begin{tabular}{|c|c|c|c|c|}
\hline Subgroups & Studies, $n$ & Prevalence (\%) & $95 \% \mathrm{Cl}$ & $\begin{array}{l}\text { Heterogeneity } \\
\text { between groups ( } p \\
\text { value) }\end{array}$ \\
\hline \multicolumn{5}{|l|}{ Type of TB } \\
\hline MDR-TB & 5 & 52.34 & $38.09-66.22$ & 0.320 \\
\hline Non-MDRTB & 20 & 43.47 & $35.20-52.65$ & \\
\hline \multicolumn{5}{|l|}{ Instrument used } \\
\hline $\mathrm{BDI}$ & 3 & 55.62 & $32.00-76.94$ & 0.073 \\
\hline HADS & 7 & 46.52 & $39.25-53.94$ & \\
\hline HDRS & 3 & 61.09 & $48.47-72.38$ & \\
\hline PHQ-9 & 12 & 38.36 & $28.52-49.26$ & \\
\hline \multicolumn{5}{|c|}{ Quality of studies } \\
\hline High & 9 & 46.06 & $33.15-58.52$ & 0.657 \\
\hline Moderate & 9 & 47.85 & $40.62-55.16$ & \\
\hline Low & 7 & 40.54 & $27.82-54.68$ & \\
\hline
\end{tabular}

MDR-TB multidrug-resistant tuberculosis, BDI Beck Depression Inventory, HADS The, Hospital Anxiety and Depression Scale, HDRS Hamilton Depression Rating Scale, PHQ-9 Patient Health Questionnaire-9

variation was not statistically significant $(p=0.320)$. In our sensitivity analysis based on the instrument used to measure depression among patients with $\mathrm{TB}$, the highest prevalence of depression was found as it was measured by HDRS (45.45\%) and the lowest prevalence was observed as measured by PHQ-9 (38.36\%). The pooled estimated prevalence of depression was $55.62 \%$ as measured by BDI and $45.52 \%$ as measured by HADS. However, the difference observed in the prevalence of depression among TB patients based on the assessment instrument used was not statistically significant ( $p=0.073$ ) (see Table 2).

Finally, we also conducted the sensitivity analysis based on the quality of included studies, the prevalence depression was found relatively equal for high-quality (46.06\%) and moderate-quality studies $(47.85 \%)$ and slightly lower for poor-quality studies $(40.54 \%$, although the difference was not statistically significant $(p=0.657)$ (see Table 2$)$.

\section{Publication bias}

The funnel plot was symmetric and Egger's regression tests provided no evidence of substantial publication bias for the prevalence of depression among patients with tuberculosis $(B=2.70, \mathrm{SE}=2.59, p=0.307)$ (see Fig. 3 ).

\section{Discussion}

This systematic review and meta-analysis of the prevalence of depression among patients with tuberculosis showed that the pooled estimated prevalence of depression was $45.55 \%$. This figure was remarkably higher than the estimated prevalence of depression in the general population which was $4.4 \%$ in 2017 [47]. Further, the pooled estimated prevalence of depression among patients with TB was much higher than the finding from a systematic review and meta-analysis conducted to assess the pooled estimated prevalence of depression and depressive symptoms among outpatients except TB that reported 27.0\% [48]. Similarly, another systematic review and meta-analysis that assessed the prevalence of depression among patients with type 1 and 2 diabetes reported $12 \%$ and $19.1 \%$, respectively [49]. These variations might be because chronic diseases such as tuberculosis, which are highly susceptible to perceived stigma and poor social support, may precipitate the depressive feelings and, in fact, clinical depression increases as the severity of the illness increases. This is also supported by evidence that suggested individuals with chronic medical illnesses, such as tuberculosis, may show much higher rates of prevalence of depression when compared to other nonchronic medical illnesses that range between 25 and $33 \%[47,50]$. Further, evidence suggests that tuberculous infection may precipitate depression or depressive symptoms in individuals due to inflammatory response and dysregulation of the hypothalamic-pituitary-adrenal axis [51]. The dysregulation of the hypothalamic-pituitary-adrenal axis has been suggested in the pathophysiology of mood disorders including depression [52].

In our subgroup analysis, the pooled prevalence of depression among MDR-TB patients was found to be $52.34 \%$ which was slightly higher than the prevalence of depression among non-MDR-TB patients (43.74), nonetheless, the variation between the observed prevalence among the two groups was not statistically significant. A recent systematic review and meta-analysis was conducted in 2018 also showed that the estimated pooled prevalence of depression among patients with MDRTB was $50 \%$ before initiation of the medications [20]. 


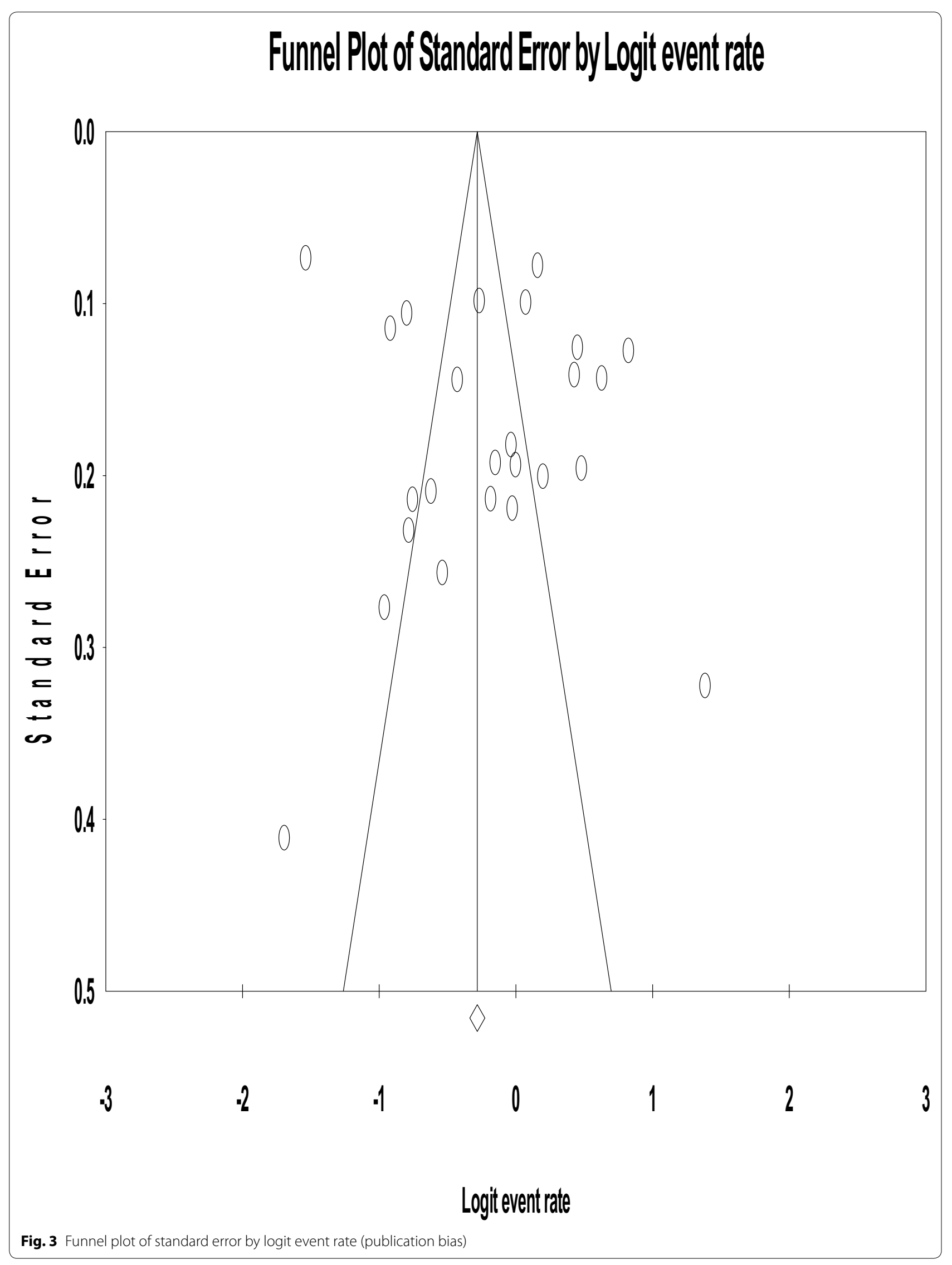


Further, this is also complemented by a finding from the Swedish Population-Based Cohort study that revealed the severity of depression increases as the severity of the illness increases [53]. These variations might be due to the severity of MDR-TB, the effect of using multiple drugs as well as lack of hope due to stressful life which might precipitate the progression of depression among patients with MDR-TB. Further, the higher rates of depression found among patients with MDR-TB may be explained by the negative psychological impact of being diagnosed and managed for MDR-TB.

We also conducted a subgroup and sensitivity analysis on the prevalence of depression among TB patients based on the instruments used to measure depression, in this analysis the highest magnitude of depression was reported as it was measured by HDRS (61.09\%) and the lowest prevalence was reported when it was measured by PHQ-9 (37.71\%). The estimated prevalence of depression was $55.6 \%$ and $46.5 \%$ as it was measured by BDI and HADS, respectively. However, our test of significance revealed that the observed difference in the magnitude of depression across different rating instruments was not statistically significant (occurred by chance) $(p=0.07)$; suggesting the use of different instruments had no significant impact on the overall pooled prevalence of depression among TB patients. The highest prevalence of depression among TB patients was observed when studies using HDRS in comparison to other instruments. This might be due to most of the studies that used HDRS to assess depression were included only MDR-TB patients. The other possible reasons for the observed variation in the prevalence of depression across the various instruments include the difference in the psychometric properties across the instruments as well as the use of different cut-off points (criteria) to define depression. For example, a study conducted to assess the psychometric comparison of PHQ-9 and HADS-D for measuring depression severity in primary care showed that both instruments differed significantly in categorizing the severity of depression [54]. Further, this is also supported by another study conducted to compare psychometric properties of the PHQ-9 and BDI-II for measuring of depression which reported that the BDI-II and PHQ-9 demonstrated adequate reliability and validity in a similar way, but differed in labeling the severity of depression or depressive symptoms in patients with medical illnesses such as tuberculosis [55].

The prevalence of depression was higher in women (51.54\%) when compared to men $(42.25 \%)$. This is line with the result of a systematic review that assessed the gender disparity in the prevalence of depression among the patient population revealed being male sex was $63 \%$ less likely to develop depression when compared to being female sex [56]. The Global Burden of Disease (GBD) study also showed that the global annual prevalence of depression among women and men was $5.5 \%$ and $3.2 \%$, respectively, in 2010, suggesting a 1.7 -fold greater risk in women [57]. For instance, findings from epidemiological studies on adults also showed that women have higher rates of the depressive disorder compared to men, suggesting on average, the ratio is $2: 1$; however, this ratio is not valid for all settings and substantially varies across different settings $[58,59]$. A systematic review and metaanalysis was conducted in 2017 synthesized data from 95 studies representing 1,922,064 people in over 90 different countries [60]. This review found a statistically significant association for the gender difference in diagnoses of depression, with $\mathrm{OR}=2.37$ at the age of 12 years. This suggests that women are more likely to have depression and depressive symptoms when compared to men. Further, evidence from the epidemiological studies also suggested that the gender differences in socialization may play a significant role in the higher prevalence of depression as females socialized to be more nurturing and sensitive to the opinions of others when compared to males [61, 62]. Moreover, a meta-analysis performed to evaluate gender differences in adults also reported that females tend to use a more emotion-focused and think about their problems over in their minds and this, in turn, may increase the vulnerability of females in developing depression when compared to males [63]. Selective preventive interventions may be warranted to reduce depression in women $[64,65]$.

\section{Strength and limitations}

Strengths of the present study are the use of predefined search strategy, conducting data extraction and quality evaluation by two independent reviewers to minimize the possible reviewer bias. Performing sensitivity and subgroup analysis based on the severity of tuberculosis, an instrument used to assess depression, the gender of the study participants and the quality of the studies were among the strengths of the current study as well. The limitations of the study include a small number of studies that were used in our subgroup analysis which may reduce the precision of the estimate. Further, the majority of the studies were conducted in low- and middle-income countries. This may suggest tuberculosis is an underestimated problem in high-income Western countries and probably depression in TB patients is even more underestimated in Western countries.

\section{Conclusion}

In summary, the results of the current study indicated that the prevalence of depression among patients with tuberculosis was relatively higher. We also found a 
higher rate of prevalence of depression among MDR-TB than non-MDR-TB patients. Further, women experience depression at higher rates when compared to men. However, the absolute reasons for the observed gender difference in the prevalence of depression need further investigations. The findings also suggest that attention needs to be given to the early screening and management of depression to alleviate this suffering. Further, given the high prevalence of depression among patients with tuberculosis, counseling and routine social support should be an integral component of tuberculosis care and management programs. Moreover, the integration of tuberculosis program with regular psychiatry services may substantially reduce the burden of depression.

\section{Abbreviations}

BDI: Beck's Depression Inventory; HADS: Hospital Anxiety and Depression Scale; HDRS: Hamilton Depression Rating Scale; MDR: Multiple drug resistance; PHQ-9: Patient Health Questionnaire-9; TB: Tuberculosis; WHO: World Health Organization.

\section{Acknowledgements}

No acknowledgements at this stage.

\section{Authors' contributions}

BD conceptualized the hypotheses, performed the search, data extraction, conducted analysis, quality assessment, write-up, drafted and approved final manuscript. GA conducted analyses, write-up and approval of final manuscript. AB participated in data extraction, write-up, and consensus and approved the final manuscript. All authors read and approved the final manuscript.

\section{Funding}

The authors declare that there is no funding.

\section{Availability of data and materials}

All data generated or analyzed during this study are included in this article.

\section{Ethics approval and consent to participate}

Not applicable.

\section{Consent for publication}

Not applicable.

\section{Competing interests}

The authors declare that they have no competing interests.

\section{Author details}

${ }^{1}$ Faculty of Health Sciences, College of Medicine and Health Sciences, Hawassa University, Hawassa, Ethiopia. ${ }^{2}$ School of Public Health, Curtin University, Perth, Australia. ${ }^{3}$ Research and Training Department, Amanuel Mental Specialized Hospital, Addis Ababa, Ethiopia.

Received: 17 April 2019 Accepted: 29 April 2020

Published online: 07 May 2020

\section{References}

1. Global tuberculosis report 2018. Geneva: World Health Organization; 2018. Licence: CCBY-NC-SA3.0IGO. https://apps.who.int/iris/handle/10665 /274453. Accessed 28 Feb 2019.

2. World Health Organization, Global tuberculosis report 2019. https://www. who.int/tb/global-report-2019. Accessed 28 Feb 2019.
3. Ugarte-Gil C, Ruiz P, Zamudio C, Canaza L, Otero L, Kruger H, et al. Association of major depressive episode with negative outcomes of tuberculosis treatment. PLoS ONE. 2013:8:e69514.

4. Munro SA, Lewin SA, Smith HJ, Engel ME, Fretheim A, Volmink J. Patient adherence to tuberculosis treatment: a systematic review of qualitative research. PLoS Med. 2007;4:e238.

5. American Psychiatric Association. Diagnostic and statistical manual of mental disorders, 5th ed. (DSM-5). Washington, DC: American Psychiatric Publishing; 2013. https://psycnet.apa.org/record/2013-14907-000. Accessed 28 Feb 2019.

6. World Health Organization, Depression report 2019, https://www.who. int/news-room/fact-sheets/detail/depression. Accessed 28 Feb 2019.

7. Moussavi S, Chatterji S, Verdes E, Tandon A, Patel V, Ustun B. Depression, chronic diseases, and decrements in health: results from the World Health Surveys. Lancet. 2007;370(9590):851-8.

8. Solomon S. Depression: let's talk. J Curr Res Sci Med. 2017;3(1):1.

9. Picco L, Subramaniam M, Abdin E, Vaingankar JA, Chong SA. Gender differences in major depressive disorder: findings from the Singapore Mental Health Study. Singap Med J. 2017;58:649-55.

10. Pachi A, Bratis D, Moussas G, Tselebis A. Psychiatric morbidity and other factors affecting treatment adherence in pulmonary tuberculosis patients. Tuberc Res Treat. 2013. https://doi.org/10.1155/2013/489865.

11. Ambaw F, Mayston R, Hanlon C, Alem A. Depression among patients with tuberculosis: determinants, course and impact on pathways to care and treatment outcomes in a primary care setting in southern Ethiopia-a study protocol. BMJ Open. 2015;5:e007653.

12. Yen YF, Chung MS, Hu HY, Lai YJ, Huang LY, Lin YS, et al. Association of pulmonary tuberculosis and ethambutol with incident depressive disorder: a nationwide, population-based cohort study. J Clin Psychiatry. 2015;76(4):e505-11.

13. Sweetland A, Oquendo M, Wickramaratne P, Weissman M, Wainberg M. Depression: a silent driver of the global tuberculosis epidemic. World Psychiatry. 2014;13(3):325-6.

14. Ugarte-Gil C, Ruiz P, Zamudio C, Canaza L, Otero L, Kruger H, Seas C. Association of major depressive episode with negative outcomes of tuberculosis treatment. PLoS ONE. 2013;8(7):e69514.

15. Husain MO, Dearman SP, Chaudhry IB, Rizvi N, Waheed W. The relationship between anxiety, depression and illness perception in tuberculosis patients in Pakistan. Clin Pract Epidemiol Ment Health. 2008:4:4

16. Manmilena A, Octivluiza N, Cosmina B, Antigona T, Dana A. Depressive syndrome, anxiety and illness perception in tuberculosis patients. Recent Res Mod Med. 2010:978:243-8.

17. Georgios M, Athanasios T, Athanasios K, Dimitra S, loannis I, Dionisios B, et al. A, comparative study of anxiety and depression in patients with bronchial asthma, chronic obstructive pulmonary disease and tuberculosis in a general hospital of chest diseases. Ann Gen Psychiatry. 2008;7:7.

18. Ige OM, Lasebikan VO. Prevalence of depression in tuberculosis patients in comparison with non-tuberculosis family contacts visiting the DOTS clinic in a Nigerian tertiary care hospital and its correlation with disease pattern. Ment Health Fam Med. 2011;8(4):235-41.

19. Duko B, Gebeyehu A, Ayano G. Prevalence and correlates of depression and anxiety among patients with tuberculosis at WolaitaSodo University Hospital and Sodo Health Center, WolaitaSodo, South Ethiopia, Cross sectional study. BMC Psychiatry. 2015;15:214.

20. Alene KA, Clements ACA, McBryde ES, Jaramillo E, Lonnroth K, Shaweno $D$, et al. Mental health disorders, social stressors, and health-related quality of life in patients with multidrug-resistant tuberculosis: a systematic review and meta-analysis. J Infect. 2018;77(5):357-67.

21. Reviews UoYCf, Dissemination. Systematic reviews: CRD's guidance for undertaking reviews in health care: University of York, Centre for Reviews \& Dissemination; 2009. https://www.york.ac.uk/media/crd/Systematic Reviews.pdf. Accessed 28 Feb 2019.

22. Stang A. Critical evaluation of the Newcastle-Ottawa scale for the assessment of the quality of nonrandomized studies in meta-analyses. Eur Epidemiol. 2010;25(9):603-5.

23. Landis JR, Koch GG. The measurement of observer agreement for categorical data. Biometrics. 1977;33(1):159-74.

24. Borenstein M, Hedges LV, Higgins J, Rothstein HR. A basic introduction to fixed-effect and random-effects models for meta-analysis. Res Synth Methods. 2010;1(2):97-111. 
25. Higgins JP, Thompson SG, Deeks JJ, Altman DG. Measuring inconsistency in meta-analyses. Br Med J. 2003:327(7414):557.

26. Aamir S. Co-morbid anxiety and depression among pulmonary tuberculosis patients. J Coll Physicians Surg Pak. 2010;20(10):703-4.

27. Anwar MS, Dogar IA, Sohail H, Mehdi Z, Azam M, Niaz O, et al. Prevalence of depression among tuberculosis patients, A.P.M.C 2010;4(2). http:// applications.emro.who.int/imemrf/Ann_Punjab_Med_Coll/Ann_Punja b_Med_Coll_2010_4_2_133_137.pdf.

28. Javaid A, Mehreen S, Khan MA, Ashiq N, Ihtesham M, et al. Depression and its associated factors with multidrug-resistant tuberculosis at baseline. J Depress Anxiety. 2017;6:253.

29. Rizvi N. Frequency of depression and anxiety among tuberculosis patients. J Tuberc Res. 2016;4:183-90.

30. Mehreen S, Khan MA, Basit A, Ashiq N, Javaid A. Frequency of depression in multidrug-resistant tuberculosis patients: an experience from a Tertiary care Hospital. Pak J Chest Med. 2015;21(4):149-54.

31. Ahmed MM, Mazhar M, Zaidi A. Depression in tuberculosis patients and its relationship to socio demographic factors. J Rawalpindi Med Coll. 2016;20(4):296-9.

32. Ravi CS, Dinesh DS, Neeraj K, Manish KT, Pankaj K. Assessment of the frequency of depression and anxiety among tuberculosis patients at a tertiary care health centre. A cross sectional study. Eur J Pharm Med Res. 2018;5(4):496-9.

33. Kumar K, Kumar A, Chandra P, Kansal HM. A study of prevalence of depression and anxiety in patients suffering from tuberculosis. J Fam Med Prim Care. 2016;5:150-3.

34. Basu G, Chatterjee C, Singh R, Biswas S. Prevalence of depression in tuberculosis patients: an experience from a DOTS clinic. IJRRMS. 2012;2(4):14-7.

35. Dahiya S, Kumar SK, Kumar N. Prevalence of depression among tuberculosis patients. Sch J App Med Sci. 2017;5(6C):2212-5.

36. Balaji AL. Depression in patients with pulmonary tuberculosis in a tertiary care general hospital. Asian J Psychiatry. 2013;6:251-2.

37. Chandra N, Sheth S, Mehta R. Socio-demographic, psychosocial factors in MDR and XDR-Tb with psychiatric co morbidities and their relation with drug adherence. IOSR J Dent Med Sci. 2017;16(1):05-8.

38. Das M, Isaakidis P, Van den Bergh R, Kumar AM, Nagaraja SB, Valikayath A, Jha S, Jadhav B, Ladomirska J. HIV, multidrug-resistant TB and depressive symptoms: when three conditions collide. Glob Health Action. 2014;7(1):24912.

39. Baba Al, Abdullah DY, Suleiman IK. Depression co-morbidity among patients with tuberculosis in a university teaching hospital outpatient clinic in Nigeria. J Ment Health Fam Med. 2009:6(3):133-8.

40. Larson EH, Moverman HY, Saito S, Frederix K, Pitt B, Maama-Maime L, Howard AA. Depressive symptoms and hazardous/harmful alcohol use are prevalent and correlate with stigma among TB-HIV patients in Lesotho. Int JTuberc Lung Dis. 2017;21(11):S34-41.

41. Dasa T, Roba A, Weldegebreal F, et al. Prevalence and associated factors of depression among tuberculosis patients in Eastern Ethiopia. BMC Psychiatry. 2019;19:82.

42. Molla A, Mekuriaw B, Kerebih H. Depression and associated factors among patients with tuberculosis in Ethiopia: a cross-sectional study. Neuropsychiatr Dis Treat. 2019;8(15):1887-93.

43. Dos Santos APC, Lazzari TK, Silva DR. Health-related quality of life, depression and anxiety in hospitalized patients with tuberculosis. Tuberc Respir Dis. 2017:80:69-76.

44. Wang X, Li X, Zhang Q, Zhang J, Chen H, Xu W, Fu Y, Wang Q, Kang J, Hou $G$. A survey of anxiety and depressive symptoms in pulmonary tuberculosis patients with and without tracheobronchial tuberculosis. Front Psychiatry. 2018:9:308.

45. Kehbila J, Ekabe CJ, Aminde LN, Jacques JN, Nde PF, Monekosso JL. Prevalence and correlates of depressive symptoms in adult patients with pulmonary tuberculosis in the Southwest Region of Cameroon. Infect Dis Poverty. 2016;5:51.

46. YIlmaz A, Dedel O. Assessment of anxiety, depression, loneliness and stigmatization in patients with tuberculosis. Acta Paul Enferm. 2016;29(5):549-57.
47. WHO global estimates on depression and other common mental disorders. 2017 https://apps.who.int/iris/bitstream/handle/10665/254610/ WHO-MSD-MER-2017.2-eng.pdf? sequence=1. Accessed 28 Feb 2019.

48. Wang J, Wu X, Lai W, et al. Prevalence of depression and depressive symptoms among outpatients: a systematic review and meta-analysis. BMJ Open. 2017;7:e017173. https://doi.org/10.1136/bmjopen-2017-017173.

49. Roy T, Lloyd CE. Epidemiology of depression and diabetes: a systematic review. J Affect Disord. 2012;142:58-21.

50. Dealing with chronic illnesses and depression. https://www.webmd .com/depression/depression-caused-chronic-illness\#1.

51. Bozza W, D'Attilio L, Mahuad CV, et al. Altered cortisol/DHEA ratio in tuberculosis patients and its relationship with abnormalities in the mycobacterial-driven cytokine production by peripheral blood mononuclear cells. Scand J Immunol. 2007:66:97-103.

52. Keller J, Gomez R, Williams G, Lembke A, Lazzeroni L, Murphy GM Jr, Schatzberg AF. HPA axis in major depression: cortisol, clinical symptomatology and genetic variation predict cognition. Mol Psychiatry. 2017:22(4):527-36. https://doi.org/10.1038/mp.2016.120.

53. Almas A, Forsell $Y$, lqbal R, Janszky I, Moller J. Severity of depression, anxious distress and the risk of cardiovascular disease in a Swedish population-based cohort. PLoS ONE. 2015;10(10):e0140742. https://doi. org/10.1371/journal.pone.0140742.

54. Cameron IM, Crawford JR, Lawton K, Reid IC. Psychometric comparison of PHQ-9 and HADS for measuring depression severity in primary care. $\mathrm{Br} \mathrm{J}$ Gen Pract. 2008;58(546):32-6.

55. Titov N, Dear BF, McMillan D, Anderson T, Zou J, Sunderland M. Psychometric comparison of the PHQ-9 and BDI-II for measuring response during treatment of depression. Cogn Behav Ther. 2011;40(2):126-36.

56. Abate KH. Gender disparity in prevalence of depression among patient population: a systematic review. Ethiop J Health Sci. 2013;23(3):283-8.

57. Whiteford HA, Degenhardt L, Rehm J, Baxter AJ, Ferrari AJ, Erskine HE, et al. Global burden of disease attributable to mental and substance use disorders: findings from the Global Burden of Disease Study 2010. Lancet. 2013;382(9904):1575-86.

58. Andrade $L$, et al. The epidemiology of major depressive episodes: results from the International Consortium of Psychiatric Epidemiology (ICPE) Surveys. Int J Methods Psychiatr Res. 2003;12:3-21.

59. Bromet E, Andrade LH, Hwang I, Sampson NA, Alonso J, de Girolamo G, Kessler RC. Cross-national epidemiology of DSM-IV major depressive episode. BMC Med. 2011;9:90. https://doi.org/10.1186/1741-7015-9-90.

60. Salk RH, Hyde JS, Abramson LY. Gender differences in depression in representative national samples: meta-analyses of diagnoses and symptoms. Psychol Bull. 2017;143(8):783-822.

61. Albert PR. Why is depression more prevalent in women? J Psychiatry Neurosci. 2015;40(4):219-21.

62. Altemus M, Sarvaiya N, Epperson CN. Sex differences in anxiety and depression clinical perspectives. Front Neuroendocrinol. 2014;35(3):320-30.

63. Johnson DP, Whisman MA. Gender differences in rumination: a metaanalysis. Pers Individ Dif. 2013;55(4):367-74. https://doi.org/10.1016/j. paid.2013.03.019.

64. Muñoz RF, Cuijpers P, Smit F, Barrera AZ, Leykin Y. Prevention of major depression. Ann Rev Clin Psychol. 2010;6(1):181-212.

65. Zlotnick C, Miller IW, Pearlstein T, Howard M, Sweeney P. A preventive intervention for pregnant women on public assistance at risk for postpartum depression. Am J Psychiatry. 2006;163(8):1443-5.

\section{Publisher's Note}

Springer Nature remains neutral with regard to jurisdictional claims in published maps and institutional affiliations. 